\title{
Efficacy of a commercial herbal formula in chicken experimental coccidiosis
}

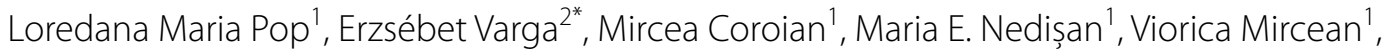 \\ Mirabela Oana Dumitrache ${ }^{1}$, Lénárd Farczádi ${ }^{3}$, Ibolya Fülöp ${ }^{4}$, Mircea Dumitru Croitoru ${ }^{4}$, Mihaly Fazakas ${ }^{2}$ \\ and Adriana Györke ${ }^{1^{*}}$
}

\begin{abstract}
Background: Coccidiosis represents a serious threat to the poultry industry, affecting production and causing high morbidity, mortality and significant costs resulting from treatment and prophylaxis. In-feed anticoccidials have been used for decades for managing avian coccidiosis and were very effective until drug resistance emerged. The use of natural remedies has become a promising alternative in combating coccidiosis in chickens. Therefore, the purpose of the present study was to assess the efficiency of a commercial herbal formula $(\mathrm{H})$, as oral liquid preparations, in experimental chicken coccidiosis.

Methods: Two independent controlled battery experiments (BE1 and BE2) were designed and the product was tested in 3 different formulas ( $\mathrm{H} 1, \mathrm{H} 2$ and $\mathrm{H} 3): \mathrm{H} 1$ contained a propylene glycol extract of Allium sativum and Thymus serpyllum; $\mathrm{H} 2$ contained Origanum vulgare, Satureja hortensis and Chelidonium majus; and H3 contained Allium sativum, Urtica dioica, Inula helenium, Glycyrrhiza glabra, Rosmarinus officinalis, Chelidonium majus, Thymus serpyllum, Tanacetum vulgare and Coriandrum sativum. Chickens were divided into five groups for each BE as follows: (i) uninfected untreated control (UU1, UU2); (ii) infected untreated control (IU1, IU2); (iii) infected treated with amprolium (ITA1, ITA2); and (iv, v) two experimental groups infected treated with $\mathrm{H} 1$ (ITH1) and $\mathrm{H} 2$ (ITH2) formulas in the BE1 and with H3 (ITH3-5 and ITH3-10) formula in the BE2. The chickens from infected groups were challenged with 5000 (BE1) and 50,000 (BE2) sporulated oocysts of Eimeria spp. (E. acervulina, E. tenella and E. maxima), respectively. The anticoccidial efficacy was assessed by recording the following: oocysts output (OPG), lesion score (LS), weight gain (WG), feed conversion ratio (FCR) and anticoccidial index (ACl). Additionally, polyphenolics and flavonoids (caffeic-chlorogenic acid, apigenin, kaempferol, luteolin, quercitin, quercitrin) from herb extracts found in $\mathrm{H} 3$ formula were determined by the liquid chromatography-tandem mass spectrometry (LC-MS/MS) method.
\end{abstract}

Results: $\mathrm{H} 1$ and $\mathrm{H} 2$ reduced the $W G$, and increased the FCR and $\mathrm{OPG}$ compared with controls. $\mathrm{H} 1$ reduced the duodenal lesions, whilst $\mathrm{H} 2$ reduced the caecal lesions, compared with control. H3 decreased the OPG of Eimeria spp., reduced the total lesion score and improved the zootechnical performance (weight gain and feed conversion ratio). According to $\mathrm{ACl}$ value, $\mathrm{H} 1$ and $\mathrm{H} 2$ had no efficacy on Eimeria spp. infection, but $\mathrm{H} 3$ had good to marked anticoccidial effect, the ACl being slightly greater in the group ITH3-5. According to the results of LC-MS/MS, the concentration of polyphenols in $\mathrm{H} 3$ formula was the highest, the sum of chlorogenic acid and caffeic acid being $914.9 \mu \mathrm{g} / \mathrm{ml}$.

\footnotetext{
*Correspondence: erzsebet.varga@umftgm.ro;

adriana.gyorke@usamvcluj.ro

${ }^{1}$ Department of Parasitology and Parasitic Diseases, Faculty of Veterinary

Medicine, University of Agricultural Sciences and Veterinary Medicine

Cluj-Napoca, Calea Mănăştur 3-5, 400372 Cluj-Napoca, Romania

2 Department of Pharmacognosy and Phytotherapy, Faculty of Pharmacy,

University of Medicine, Pharmacy, Sciences and Technology of Târgu

Mureș, 38 Gheorghe Marinescu, 540139 Târgu Mureș, Romania

Full list of author information is available at the end of the article
}

(c) The Author(s) 2019. This article is distributed under the terms of the Creative Commons Attribution 4.0 International License (http://creativecommons.org/licenses/by/4.0/), which permits unrestricted use, distribution, and reproduction in any medium, provided you give appropriate credit to the original author(s) and the source, provide a link to the Creative Commons license, and indicate if changes were made. The Creative Commons Public Domain Dedication waiver (http://creativecommons.org/ publicdomain/zero/1.0/) applies to the data made available in this article, unless otherwise stated. 
Conclusions: $\mathrm{H} 3$ formula is a promising natural anticoccidial and field trials are recommended in order to validate the obtained data.

Keywords: Eimeria, Herbal extract, Broiler chickens, Anticoccidial effect, Polyphenols, LC-MS/MS

\section{Background}

Coccidiosis is a parasitic disease caused by seven species of the genus Eimeria with different localizations within the intestinal tract of chickens. Eimeria acervulina, E. maxima and E. tenella are the most prevalent species in broilers in the intensive poultry management system [1, 2]. The disease represents a serious threat for the poultry industry, affecting the production, and causing high morbidity, mortality and significant economic loss due to the associated costs of treatment and prophylaxis. Global financial losses due to coccidiosis have been estimated at three billion USD per annum [3]. In-feed anticoccidials have been used for decades for managing avian coccidiosis and they were very effective until drug resistance emerged. To date, Eimeria strains have gained resistance to all known coccidiostats, and new anticoccidials are unlikely to be developed, mainly because of strict legislative regulations on the use of in-feed drugs and growing concerns in the general population about the chemical residues in poultry products [4-6]. Over the past years, the consumption of poultry meat has grown consistently, especially because it represents a fairly cheap source of food with lower production costs and accepted by all religions [7]. There is also a higher interest from the consumer in organic poultry production and a great demand for natural and healthier products [8]. In this context, the use of natural remedies has become a promising alternative to anticoccidial drugs [9]. Numerous plant-based products have been found to be effective at treating chicken coccidiosis: Artemisia annua and artemisinin [10, 11], oregano [12], garlic [13], neem [14], different species of Aloe [15], green tea [16], sugar cane [17], turmeric [18] and many others [9, 19-21]. Additionally, commercially available herbal combinations are already used in some countries for coccidiosis control [19]. Most of these natural compounds do not always aim directly at the parasites but have immunomodulatory effects, antioxidative or anti-inflammatory properties and act on the intestinal tract, thus helping the host organism to fight against the coccidial infection $[9,19]$. Moreover, the plant extracts can have a direct effect on the parasites, by altering the process of oocyst wall formation and inhibiting sporulation [22, 23], or by destroying the sporozoites [24]. Furthermore, there is a lower risk of developing resistance to these natural substances compared to anticoccidial drugs [21]. Furthermore, herbal extracts could improve recovery after coccidiosis $[25,26]$.
Flavonoids and other polyphenols have been reported to be responsible for most of the biological properties of the herbs, including the anticoccidial potential [27].

Therefore, the purpose of the present study was to assess the effect of a commercial multi-plant extract compound, in experimental coccidiosis in broiler chickens. The composition of the herbal extract was designed on the basis of a literature search for effective anticoccidial natural compounds.

\section{Methods}

\section{Animals and experimental design}

Two independent controlled battery experiments (BE) were designed in order to assess the efficacy of a commercial herbal product $(\mathrm{H})$, in three different formulas of propylene glycol/alcoholic herbal extracts. In the first $\mathrm{BE}$ (BE1), the anticoccidial effect of the first (H1) and second (H2) formulas was evaluated. The third formula (H3) was evaluated during the second BE (BE2).

One hundred one-day-old ROSS 308 hybrid broiler chickens were purchased from S.C. VIS AVIS S.A. (Vadu Crişului, Bihor, Romania) for each of the two BE. They were housed in batteries in dedicated facilities at the University of Agricultural Sciences and Veterinary Medicine Cluj-Napoca. At 14-days-old, broiler chickens were randomly divided in five groups, each with three replicates of five chickens/cage $(n=15)$. In both BE the experimental groups were represented by: (i) negative control, uninfected and untreated (UU1, UU2); (ii) positive control, infected and untreated (IU1, IU2); (iii) treatment control, infected and treated with amprolium (ITA1, ITA2); and (iv, v) two experimental groups, infected and treated with H1 (ITH1) and H2 (ITH2) formulas in the BE1and with H3 (ITH3-5 and ITH3-10) formula in the BE2.

On the same day, the broiler chickens were experimentally infected by the crop-route using insulin syringe, with $1 \mathrm{ml}$ of a mixed suspension of fresh sporulated oocysts (BE1 $5 \times 10^{3}$ oocysts/chicken; BE2 $5 \times 10^{4}$ oocysts/ chicken) containing E. acervulina, E. tenella and E. max$i m a$. The strains were isolated in 2012 from a broiler farm and the species were identified by PCR [28]. The number of oocysts per milliliter was determined using a FuchsRosenthal chamber and adjusted according to sporulation rate.

The control and experimental treatments were given via drinking water from 14 until 24 days of age, ad libitum. Chickens from ITA1 and ITA2 groups were treated 
with amprolium (Amprolium $20 \%{ }^{\circledR}$ water-soluble powder; Romvac Company S.A., Voluntari, Ilfov, Romania) as doses of 2.5 (BE1) and $5 \mathrm{~g} / \mathrm{l}$ water (BE2), respectively. $\mathrm{H} 1$ and $\mathrm{H} 2$ herbal formulas were given as doses of $10 \mathrm{ml} / \mathrm{l}$ drinking water (BE1) and $\mathrm{H} 3$ herbal formula as doses of 5 (ITH3-5) and 10 (ITH3-10) $\mathrm{ml} / \mathrm{l}$ drinking water (BE2).

The chickens were fed with standard starter (1-13 days-old) and grower (14-24 days-old) feed free of anticoccidials.

\section{Herbal formulas}

The commercial herbal formula was supplied by S.C. PROMEDIVET S.R.L (Sovata, Mureș, Romania) as oral liquid preparations. The anticoccidial efficacy in chicken coccidiosis was evaluated for three different extracts named $\mathrm{H} 1, \mathrm{H} 2$ and $\mathrm{H} 3$. The extracts were obtained from grounded dried plants after maceration in propylene glycol (20 kg of dried plants in $120 \mathrm{l}$ of propylene glycol) for 14 days and cold pressing.

H1 contained extracts from bulbs of Allium sativum (garlic) and leaves of Thymus serpyllum (wild thyme) in equal proportions. H2 was a mixture of extracts from leaves of Origanum vulgare (oregano) 40\%, Satureja hortensis (summer savory) $30 \%$ and Chelidonium majus (greater celandine) 30\%. H3 contained extracts from nine herbs: roots of Urtica dioica (nettle) 10\%, Inula helenium (elecampane) 15\%, Glycyrrhiza glabra (licorice) 10\%, bulbs of Allium sativum 10\%, leaves of Rosmarinus officinalis (rosemary) 10\%, Chelidonium majus 10\%, Thymus serpyllum 15\%, flowers of Tanacetum vulgare (tansy) 10\% and seeds of Coriandrum sativum (coriander) $10 \%$.

\section{Liquid chromatography tandem mass spectrometry}

The H3 formula was analyzed by liquid chromatography tandem mass spectrometry (LC-MS). One hundred microliters of $\mathrm{H} 3$ formula was mixed with $900 \mu \mathrm{l}$ of purified water, then centrifuged at $10,000 \times \mathrm{rpm}$ for $10 \mathrm{~min}$ and filtered using nylon micro pore $0.45 \mu \mathrm{m}$ filters. Solutions were transferred to HPLC vials and $5 \mu \mathrm{l}$ of the obtained samples were injected into the LC-MS system.

Chromatographic separation of analytes was performed using a NUCLEODUR C18 Gravity, $3 \mu \mathrm{m}$, $150 \times 3 \mathrm{~mm}$ (Macherey-Nagel, Düren, Germany) with a mobile phase consisting of $0.2 \%$ formic acid in water and methanol in gradient elution, with a flow rate of $0.6 \mathrm{ml} /$ min. Detection was carried out in multiple reactions monitoring mode (SRM). Ionization of analytes was performed using negative electrospray ionization mode. Ionization parameters used for the ionization source were as follows: spray voltage, $2500 \mathrm{~V}$; vaporizer temperature, $350^{\circ} \mathrm{C}$; ion gas source 1,25 ; ion gas source 2,25 ; curtain gas, 10; declustering potential, 100; ion release delay, 30; ion release width, 15. Sample run-time was $30 \mathrm{~min}$ per sample.

Standard solutions of each analyte (chlorogenic acid, caffeic acid, quercitrin, luteolin, quercetin, apigenin and kaempferol) $(100 \mu \mathrm{g} / \mathrm{ml})$ were prepared in methanol. For analysis, standard solutions were mixed in methanol to a final concentration of $10 \mu \mathrm{g} / \mathrm{ml}$ for each analyte. Furthermore, the mixture was diluted to the following concentrations: 0.1 (lower limit of quantification, LLOQ), 0.25, $0.5,1$ and $10 \mu \mathrm{g} / \mathrm{ml}$. The calibration of standard curve solutions was prepared by diluting $100 \mu \mathrm{l}$ of each standard solution with $900 \mu \mathrm{l}$ of purified water.

\section{Anticoccidial efficacy evaluation}

The efficacy of the herbal formulas in experimental coccidiosis in broiler chickens was assessed by recording and calculating the number of oocysts shedded per gram of feces (OPG), lesion score (LS), mortality rate (MR), body weight gain (BWG), feed conversion ratio (FCR) and anticoccidial index (ACI).

The feces were collected on days 5, 7 and 10, from all 3 cages/group individually and the OPG was determined by duplicate counts of duplicate fecal slurries from each cage by using the McMaster method [29]. The detection limit was 12 oocysts/g feces. The LS was assessed on day 7 post-infection (pi) for eight chickens per group by using the scoring system of Johnson \& Reid [30], according to the severity of lesions in duodenum, jejunum plus ileum and caeca. Chickens were weighed individually at the beginning of the experiments and at 7 days post-infection in order to calculate the body weight gain. The amount of feed given to the chickens was weighed daily for each cage, in order to calculate FCR, as the ratio between the amount of feed consumed per body weight gain of the chickens.

The ACI was calculated after the formula: $\mathrm{ACI}=(\% \mathrm{~S}+\% \mathrm{RGW})-(\mathrm{LI}+\mathrm{OI})[31]$, where $\% \mathrm{~S}$ is the percentage of survival, \%RGW is the percentage of relative weight gain $(\mathrm{RWG}=\mathrm{BWG} \times 100 /$ untreated group BWG), LI is the lesion index as the lesion score multiplied by 10 and OI is the oocyst index as (OPG output of each experimental group/OPG output of the infectedunmedicated control) $\times 100$. The interpretation of the results was made as follows: "lack of anticoccidian activity" when the value was lower than 120 , "partially effective" at values of 120-160 and "very effective" at values higher than 160 [31].

\section{Statistical analysis}

The data were processed with MedCalc Software v.18 (MedCalc Software bvba, Ostend, Belgium; https:// 
Table 1 The effect of the herbal product $\mathrm{H}$ on lesion score and performance parameters in experimental groups of chickens challenged with Eimeria spp. (E. acervulina, E. maxima and E. tenella) compared with control groups

\begin{tabular}{|c|c|c|c|c|c|}
\hline & \multicolumn{3}{|l|}{ Lesion score } & \multirow[t]{2}{*}{ BWG } & \multirow[t]{2}{*}{ FCR } \\
\hline & Duodenum & Caecum & Total & & \\
\hline \multicolumn{6}{|l|}{ BE1 } \\
\hline UU1 & 0 & 0 & 0 & $55.81 \pm 2.54$ & $1.97 \pm 0.11$ \\
\hline IU1 & $0.4 \pm 0.2$ & $0.5 \pm 0.2$ & $0.9 \pm 0.3$ & $54.51 \pm 1.55$ & $1.77 \pm 0.19$ \\
\hline ITA1 & $0.1 \pm 0.1$ & $0.1 \pm 0.1$ & $0.3 \pm 0.2$ & $53.57 \pm 2.52$ & $1.64 \pm 0.31$ \\
\hline ITH1 & 0 & $0.5 \pm 0.2$ & $0.5 \pm 0.2$ & $53.30 \pm 0.83$ & $1.99 \pm 0.30$ \\
\hline $\mathrm{ITH} 2$ & $0.4 \pm 0.2$ & $0.1 \pm 0.1$ & $0.5 \pm 0.2$ & $47.07 \pm 1.74^{*}$ & $2.24 \pm 0.08$ \\
\hline \multicolumn{6}{|l|}{ BE2 } \\
\hline UU2 & 0 & 0 & 0 & $46.89 \pm 2.68$ & $1.58 \pm 0.17$ \\
\hline IU2 & $1.33 \pm 0.56$ & $1.0 \pm 0.00$ & $2.33 \pm 0.56$ & $34.91 \pm 4.39$ & $2.04 \pm 0.13$ \\
\hline ITA2 & $0.00 \pm 0.00^{*}$ & $0.8 \pm 0.20$ & $0.8 \pm 0.20^{*}$ & $42.36 \pm 2.08$ & $1.61 \pm 0.02$ \\
\hline ITH3-5 & $0.83 \pm 0.54$ & $0.33 \pm 0.21^{*}$ & $1.17 \pm 0.65$ & $40.57 \pm 1.92$ & $1.78 \pm 0.03$ \\
\hline ITH3-10 & $0.83 \pm 0.48$ & $0.5 \pm 0.22$ & $1.33 \pm 0.42$ & $39.80 \pm 2.83$ & $1.78 \pm 0.02$ \\
\hline
\end{tabular}

${ }^{*} P<0.05$, Mann-Whitney test (independent samples) (MedCalc)

Abbreviations: $\mathrm{BE}$, battery experiment $\left(5 \times 10^{3}\right.$ oocysts/chicken in BE1 and $5 \times 10^{4}$ oocysts/chicken in BE2); UU1, 2, negative control group; IU1, 2, positive control group; ITA1,2, Amprolium ${ }^{\circledR} 20 \%$ (Romvac Company SA, Voluntari, Ilfov, Romania), soluble powder treated group; ITH1, ITH2, ITH3-5 and ITH3-10, experimental groups treated with the herbal product in different compositions, $10 \mathrm{ml} / \mathrm{I}$ water (ITH1, ITH2 and ITH3-10) and 5 ml/I water (ITH3-5); BWG, body weight gain; FCR: feed conversion ratio

www.medcalc.org). The arithmetic mean and standard error were calculated for each assessed parameter and for each group. ANOVA (repeated measures analysis of variance) was used for OPG and body weight gain, and the Kruskal-Wallis test was used for lesion score. Differences were considered statistically significant if the $P \leq 0.05$. The experimental groups were compared with both positive and negative control groups and also with group A.

\section{Results}

\section{First battery experiment}

The OPG of groups treated with $\mathrm{H} 1$ and $\mathrm{H} 2$ formulas was significantly higher compared with the positive control (IU1) or ITA1 groups on day 7 post-infection (p.i.) $\left(F_{(3,11)}=28.13, P<0.001\right) \quad$ (Fig. 1$)$. The mortality rate was 0 for all experimental groups. During the necropsy, lesions due to Eimeria spp. infection were identified in duodenum and caecum in all infected groups. In
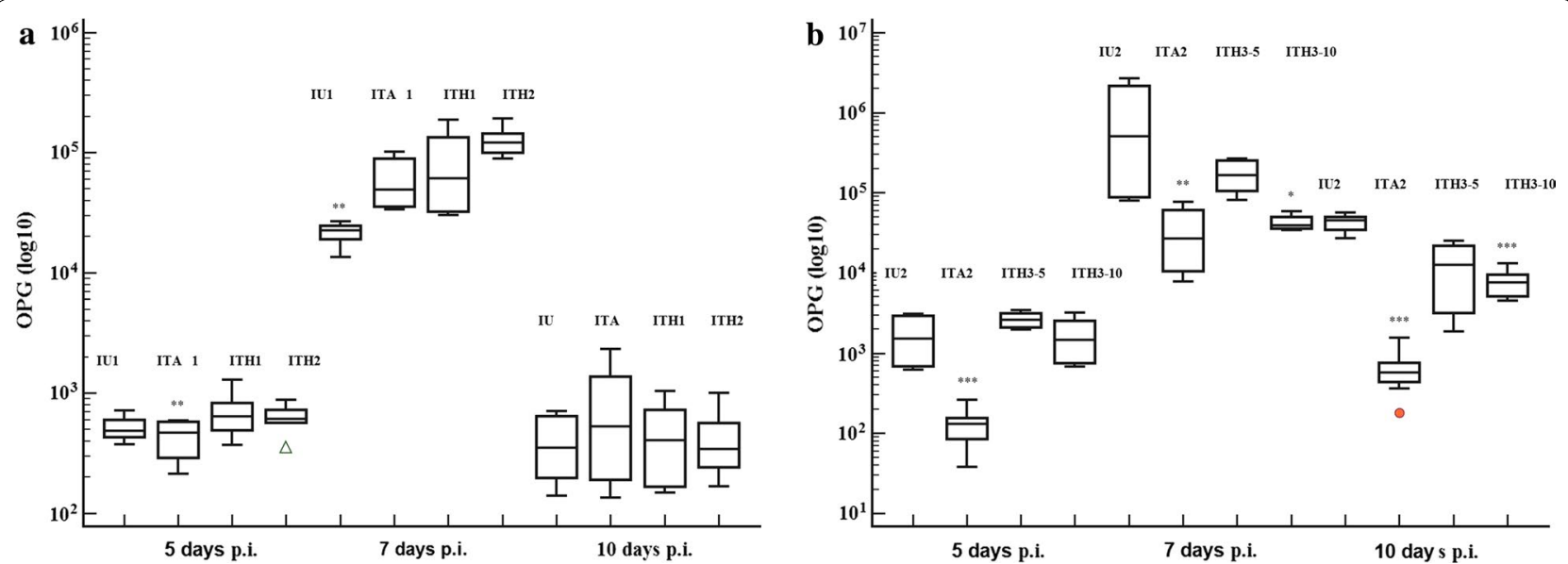

Fig. 1 Dynamics of mean oocysts number/g of feces in experimental groups of chickens infected with Eimeria spp. (E. acervulina, E. maxima and E. tenella) and treated with the herbal product in different compositions compared with positive and amprolium control groups. a First battery experiment when chickens were infected with $5 \times 10^{3}$ sporulated oocysts of Eimeria spp. and treated with $\mathrm{H} 1$ and $\mathrm{H} 2$ formulas, $10 \mathrm{ml} / \mathrm{l}$ water. $\mathbf{b}$ Second battery experiment when chickens were infected with $5 \times 10^{4}$ sporulated oocysts of Eimeria spp. and treated with H3 formula, 5 (ITH3-5) and $10 \mathrm{ml} / \mathrm{l}$ water (ITH3-10) 
all experimental infected groups, the total lesion score recorded values below 1 and with no significant differences $\left(\chi^{2}=2.556, d f=3, P=0.465\right)$ between groups (Table 1). Nevertheless, the total lesion score in ITH1 and ITH2 groups was lower than the positive control group and higher than in group ITA1.

$\mathrm{H} 1$ formula prevented the emergence of E. acervulina lesions in the duodenum, but had no therapeutic/prophylactic effect on E. tenella; the lesion score in the caecum was similar with the positive control group. $\mathrm{H} 2$ formula did not prevent the occurrence of duodenal lesions, but the lesion score in the caecum was lower than in the positive control group $\left(\chi^{2}=1.588, d f=1, P=0.208\right)$ (Table 1$)$.

All experimental groups presented lower weight gains compared with the negative control group, with statistical significance in the case of group ITH2 $\left(F_{(4,9)}=7.8\right.$, $P=0.007$ ) (Table 1). The lowest weight gain was recorded in the group treated with $\mathrm{H} 2$ formula (Table 1 ). The FCR of negative and experimental groups was higher comparing with positive control group (Table 1).

According to the anticoccidial index, the $\mathrm{H} 1$ and $\mathrm{H} 2$ formulas had no efficacy on Eimeria spp. infection.

\section{Second battery experiment}

The OPG value was significantly higher in groups treated with $\mathrm{H} 3$ formula than in the group treated with amprolium but not compared with the positive control group $\left(F_{(3,7)}=19.7, P<0.001\right)$ at 5 days p.i. On days 7 and 10 p.i., the OPG of chickens treated with H3 decreased under the values of the positive group, but significantly only on day 10 p.i. $\left(F_{(3,7)}=43.44, P<0.001\right)$ (Fig. 1$)$. The group ITA2 recorded the lowest value of OPG compared with positive control and $\mathrm{H} 3$ treated groups during the entire recording period $\left(F_{(3,23)}=6.63, P=0.003\right)$.

No mortality was registered in any experimental group. The chickens from all groups, with the exception of the ITA2 group, presented lesions in the duodenum, but all chickens had lesions in the caecum. Neither 5 nor $10 \mathrm{ml} / \mathrm{l}$ water of $\mathrm{H} 3$ formula significantly reduced the duodenal lesions compared with the positive control group. H3 formula at a dose of $10 \mathrm{ml} / \mathrm{l}$ water significantly reduced the caecal lesions $(Z=2.162, P=0.031)$. Additionally, the chickens treated with $5 \mathrm{ml} \mathrm{H3/1}$ drinking water had fewer lesions than the positive control group, but with no statistical significance (Table 1). The total lesion score was reduced significantly compared with the positive control group only in the case of the ITA2 group $(Z=2.106$, $P=0.0352)$. However, the $\mathrm{H} 3$ formula at a dose of $10 \mathrm{ml} / \mathrm{l}$ water reduced the total lesion score by $50 \%$.

All the experimental groups presented lower weight gains than the negative control group $\left(F_{(4,11)}=1.78\right.$, $P=0.182$ ). However, compared with the positive control group, the chickens treated with $\mathrm{H} 3$ formula had higher weight gains and only slightly lower than the amprolium treated chickens.

The best feed conversion ratio was recorded, as expected, by the negative control group. However, the groups treated with $\mathrm{H} 3$ formula also had good feed conversion, similar to those of the uninfected chickens. The positive control group had the lowest use of feed.

The H3 formula was effective for control of experimental coccidiosis in chickens according to the anticoccidial index and it was not dose dependent (Fig. 2).

\section{Liquid chromatography tandem mass spectrometry}

A total ion chromatogram and an extracted ion chromatogram of the $\mathrm{H} 3$ formula are presented in Additional file 1: Figure S1 and Additional file 2: Figure S2, respectively. The presence of seven flavonoids and polyphenols was tested (Table 2). The concentration of polyphenols was the highest, the sum of chlorogenic acid and caffeic acid being $914.9 \mu \mathrm{g} / \mathrm{ml}$.

\section{Discussion}

Herbal remedies have been used since ancient times in medicine and have recently gained increasing popularity, especially because of the declining effectiveness of synthetic compounds and concerns of the general population about drug side effects and interactions [18]. In chicken coccidiosis, herbal extracts have been intensively studied in the recent years in the search for new alternatives to the traditional anticoccidial drugs [27]. The extensive use of anticoccidials in the poultry industry may lead to the occurrence of drug residues in meat and eggs [32]. As such, consumer interest in organic foods has been rapidly increasing in recent years. The organic requirements restrict the use of chemicals, so natural plant products may represent an effective solution for pathogen control in the organic poultry system [28].

In this frame, the present study aimed to assess the anticoccidial effect of a natural plant product in three different compositions. H1 formula, which contained garlic and wild thyme extract, totally reduced the lesions produced by E. acervulina. H2 formula, which was comprised of oregano, summer savory and greater celandine, reduced the lesions caused by E. tenella. However, the chickens medicated with these formulas presented higher OPG output compared with the positive control group. This aspect can be explained by the over-multiplication of the uninhibited Eimeria species. According to Dar et al. [33], garlic administration increases the values of serum albumin, globulin and total proteins due to its antiinflammatory and immunomodulatory action that repair the organ lesions induced by Eimeria, an aspect observed in the present study for the duodenum. ArczewskaWłosek and Świątkiewicz [26] observed an increased 

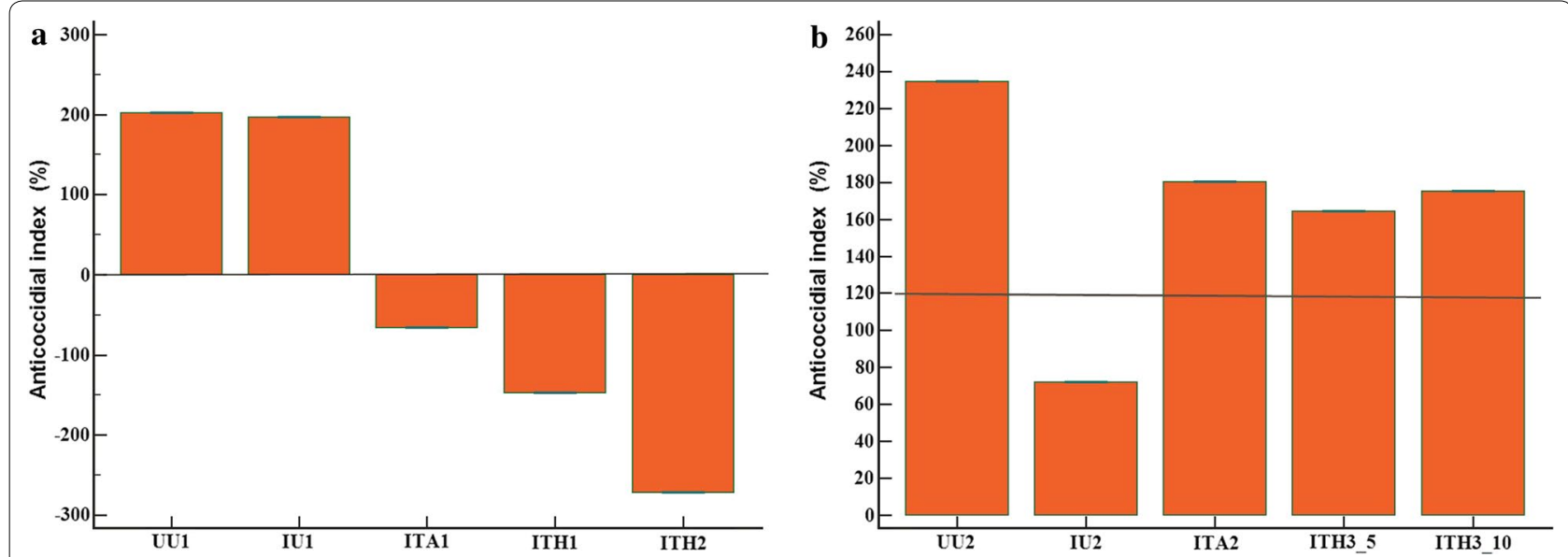

Fig. 2 Anticoccidial index in experimental groups of chickens infected with Eimeria spp. (E. acervulina, E. maxima and E. tenella) and treated with the herbal product in different compositions compared with control (negative, positive and amprolium) groups. a First battery experiment when chickens were infected with $5 \times 10^{3}$ sporulated oocysts of Eimeria spp. and treated with $\mathrm{H} 1$ and $\mathrm{H} 2$ formulas, $10 \mathrm{ml} / / \mathrm{I}$ water. b Second battery experiment when chickens were infected with $5 \times 10^{4}$ sporulated oocysts of Eimeria spp. and treated with H3 formula, 5 (ITH3-5) and $10 \mathrm{ml} / \mathrm{I}$ water (ITH310). The line at 120 represents the cut-off value for anticoccidian activity and values under the line means a lack of anticoccidian activity

Table 2 Concentration of the tested compounds in the $\mathrm{H} 3$ formula

\begin{tabular}{llll}
\hline Compound & $\begin{array}{l}\text { Concentration } \\
(\mu \mathrm{g} / \mathrm{ml})\end{array}$ & $\begin{array}{l}\text { Amount }(\mu \mathrm{g}) \text { in } \\
1 \text { I of water }(\mathrm{H3a})\end{array}$ & $\begin{array}{l}\text { Amount }(\mu \mathrm{g}) \\
\text { in 1 I of water } \\
(\mathrm{H} 3 \mathrm{~b})\end{array}$ \\
\hline Apigenin & 1.04 & 10.4 & 5.2 \\
Kaempferol & 0.23 & 2.3 & 1.1 \\
Quercetin & 0.29 & 2.9 & 1.4 \\
Luteolin & 4.93 & 49.3 & 24.6 \\
Quercitrin & 0.62 & 6.2 & 3.1 \\
Chlorogenic acid & 75.87 & 758.7 & 379.3 \\
Caffeic acid & 15.62 & 156.2 & 78.1 \\
\hline
\end{tabular}

weight gain and better feed conversion in the chickens highly infected with Eimeria spp. whose diet was supplemented with garlic extract at a level of $750 \mathrm{mg} / \mathrm{kg}$ feed. Similar to our results, the OPG was higher than in the case of the infected unmedicated group. The authors stated that the high production performances, despite of the greater number of oocysts recorded, could be the effect of reduced damage to intestinal cells or promotion of enterocyte renewal, which can provide the substrate for coccidia multiplication. However, in our study the first two formulas of the commercial herbal formula did not improve the chickens' production performance. Numerous studies have demonstrated that Origanum vulgare as aqueous extract at a concentration of $2 \mathrm{~g} / \mathrm{kg}$ feed [34] or essential oil in concentrations of 600 and $1200 \mathrm{mg} / \mathrm{kg}$ feed [35] and also Satureja hortensis powder at $5 \mathrm{~g} / \mathrm{kg}$ feed [36], or 1\% powder in feed [37] stimulates the food intake and growth of chickens. However, as in the present study, Bozkurt et al. [38] showed that the administration of an essential oil blend that contained carvacrol, 1,8-cineole, camphor, and thymol derived from oregano, laurel leaf and lavender oil did not significantly improve the broiler growth performance. The authors concluded that the magnitude of improvement in weight gain also depends on other factors like gut microflora, mucus production or host immune response, which consume part of the nutrients used for growth. In the present study, because the herbs did not present anticoccidial activity on all Eimeria species used, the coccidian infection most probably invalidated the growth promoting effects of the plants. Kim et al. [24] found that garlic metabolites enhance chickens' production performances and reduce the oocyst output in chickens challenged with $E$. acervulina, due to a direct cytotoxic effect on the coccidian sporozoites. This probably also occurred in our study based on the absence of $E$. acervulina lesions in the chickens medicated with the first formula. There are also studies that demonstrate the anticoccidial effect of Origanum vulgare essential oil on E. tenella at a level of $300 \mathrm{mg} / \mathrm{kg}$ feed [12]. In the present study the formula which contained oregano (H2) also had a good effect on reducing the lesions produced by E. tenella. A herbal extract that contained Allium sativum, Salvia officinalis, Echinacea purpurea, Thymus vulgaris and Origanum vulgare improved the performance parameters of broilers and reduced the oocyst output [39]. It seems that in a mixed coccidian infection, the combination of different herbs may represent the solution in controlling the disease. 
As shown in the present study, the multi-herb product $\mathrm{H} 3$ highly reduced the coccidian multiplication rate and reduced the severity of intestinal lesions. The product had a lower anticoccidial effect on E. acervulina, but a good effect on E. tenella (markedly reduced OPG output and medium reduced lesion score). The synergistic effects of the combined herbs enhanced the anticoccidial activity of broiler chickens medicated with H3. Some of the herbs from the mixed extract already have proven anticoccidial activity such as Allium sativum powder, supplemented in broiler feed at $0.1 \%$ [13] and Thymus serpyllum in ducks at a concentration of $2,500 \mathrm{mg} /$ $\mathrm{kg}$ [40]. These two herbs were included in the 1st tested herbal formula. Other herbs used in H3 composition like Urtica dioica, Rosmarinus officinalis, Tanacetum vulgare, Coriandrum sativum or Glycyrrhiza glabra are known to have immunomodulatory effects [33, 41-44]. Moreover, many of these plants contain flavonoids, tannins or saponins that act as antioxidants which reduce the oxidative stress caused by reactive oxygen species encountered also in coccidiosis [27]. The antioxidant capacity of a herbal product is directly linked with its anticoccidial effect [45]. As shown in LC-MS/MS, the $\mathrm{H} 3$ formula is a rich source of polyphenols. The chlorogenic acid was in high concentration, followed by the caffeic acid and the luteolin. Chlorogenic acid was found to have antibacterial and antibiofilm properties against nosocomial pathogen strains [46]. Furthermore, chlorogenic acid and caffeic acid are powerful antioxidants [47], which neutralize the reactive oxygen species that are produced during Eimeria infection, as stated above. The antioxidants can alleviate the damage to the intestinal tissue during parasite invasion by reducing the cytotoxic effects caused by the reactive oxygen species [48], and thus can explain the lower lesion score observed in the chickens treated with $\mathrm{H} 3$ formula.

\section{Conclusions}

H3 formula was effective in controlling experimental coccidiosis in chickens and can be used successfully as a natural anticoccidial. Field trials are, however, recommended in order to validate the data obtained in experimental studies.

\section{Additional files}

Additional file 1: Figure S1. Total ion chromatogram of the $\mathrm{H} 3$ formula.

Additional file 2: Figure S2. Extracted ion chromatogram of the $\mathrm{H} 3$ formula.

\section{Abbreviations}

$\mathrm{H}$ : herbal formula; $\mathrm{H} 1$ : first herbal formula; $\mathrm{H} 2$ : second herbal formula; $\mathrm{H} 3$ : third herbal formula; BE: battery experiment; BE1: first battery experiment; BE2: second battery experiment; UU1: uninfected untreated control in BE1; UU2: uninfected untreated control in BE2; IU1: infected untreated control in BE1; IU2: infected untreated control in BE2; ITA1: infected treated with amprolium in BE1; ITA2: infected treated with amprolium in BE2; ITH1: infected treated with $\mathrm{H} 110 \mathrm{ml} / \mathrm{I}$ water in $\mathrm{BE} 1$; ITH2: infected treated with $\mathrm{H} 210 \mathrm{ml} / \mathrm{I}$ water in BE1; ITH3-5: infected treated with $\mathrm{H} 35 \mathrm{ml} / \mathrm{I}$ water in BE2; ITH3-10: infected treated with $\mathrm{H} 310 \mathrm{ml} / \mathrm{I}$ water in BE2; PCR: polymerase chain reaction; LC-MS/ MS: liquid chromatography-tandem mass spectrometry; SRM: multiple reactions monitoring mode; OPG: oocysts shed per gram of feces; LS: lesion score; MR: mortality rate; WG: weight gain; FCR: feed conversion ratio; $\mathrm{ACl}$ : anticoccidial index; p.i.: post-infection; \%S: percentage survival; \%RGW: percentage of relative weight gain; Ll: the lesion index; Ol: oocyst index.

\section{Acknowledgements}

We would like to especially acknowledge the Center for Advanced Medical and Pharmaceutical Research (University of Medicine, Pharmacy, Sciences and Technology of Tîrgu Mureş) and its staff for performing phytochemical analysis.

\section{Authors' contributions}

LMP wrote the manuscript. EV wrote the manuscript (LC-MS) and prepared the samples for LC-MS. MC, MN, VM and MOD performed the study. LF performed MS measurment. IF performed statistical analyses and results calculation. MDC performed HPLC analysis. MF designed the experimental protocol. AG designed the experimental protocol and the manuscript, statistical analysis and reviewed the manuscript. All authors read and approved the final manuscript.

\section{Funding}

This work was supported by the University of Agricultural Sciences and Veterinary Medicine Cluj-Napoca (grant number 6142/10.04.2017), the University of Medicine, Pharmacy Sciences and Technology of Târgu Mureș (grant number 17972/07.12.2016) and SC Promedivet SRL.

Also, this project was funded by the Ministry of Research and Innovation of Romania, Projects for Financing the Excellence in CDI, Contract no. 37PFE/06.11.2018.

\section{Availability of data and materials}

The datasets used and/or analysed during the present study are available from the corresponding author upon reasonable request.

\section{Ethics approval and consent to participate}

The experimental protocol was approved by the Animal Ethics Committee of the University of Agricultural Sciences and Veterinary Medicine Cluj-Napoca (approval number 30314/2018).

\section{Consent for publication}

Not applicable.

\section{Competing interests}

The authors declare that they have no competing interests.

\section{Author details}

${ }^{1}$ Department of Parasitology and Parasitic Diseases, Faculty of Veterinary Medicine, University of Agricultural Sciences and Veterinary Medicine Cluj-Napoca, Calea Mănăştur 3-5, 400372 Cluj-Napoca, Romania. ${ }^{2}$ Department of Pharmacognosy and Phytotherapy, Faculty of Pharmacy, University of Medicine, Pharmacy, Sciences and Technology of Târgu Mureș, 38 Gheorghe Marinescu, 540139 Târgu Mureș, Romania. ${ }^{3}$ Center for Advanced Medical and Pharmaceutical Research, Laboratory of Chromatography LC/MS, Faculty of Pharmacy, University of Medicine, Pharmacy, Sciences and Technology of Târgu Mureș, 38 Gheorghe Marinescu, 540139 Târgu Mureș, Romania. ${ }^{4}$ Department of Toxicology and Biopharmacy, Faculty of Pharmacy, University of Medicine, Pharmacy, Sciences and Technology of Târgu Mureș, 38 Gheorghe Marinescu, 540139 Târgu Mureș, Romania. 
Received: 12 February 2019 Accepted: 3 July 2019

Published online: 12 July 2019

\section{References}

1. Haug A, Gjevre AG, Thebo P, Mattsson JG, Kaldhusdal M. Coccidial infections in commercial broilers: epidemiological aspects and comparison of Eimeria species identification by morphometric and polymerase chain reaction techniques. Avian Pathol. 2008;37:161-70.

2. Györke A, Pop L, Cozma V. Prevalence and distribution of Eimeria species in broiler chicken farms of different capacities. Parasite. 2013;20:50.

3. Dalloul R, Lillehoj H. Poultry coccidiosis: recent advancements in control measures and vaccine development. Expert Rev Vaccines. 2006;5:143-63.

4. Chapman HD. Biochemical, genetic and applied aspects of drug resistance in Eimeria parasites of the fowl. Avian Pathol. 1997;26:221-44.

5. Sundar STB, Harikrishnan TJ, Latha BR, Chandra GS, Senthil Kumar TMA. Anticoccidial drug resistance in chicken coccidiosis and promising solutions: a review. J Entomol Zool Stud. 2017;5:1526-9.

6. Blake DP, Tomley FM. Securing poultry production from the ever-present Eimeria challenge. Trends Parasitol. 2014;30:2-19.

7. Stenhouse S. The poultry industry. In: Pattison M, McMullin PF, Bradbury JM, Alexander DJ, editors. Poultry diseases. 6th ed. Philadelphia: Saunders Ltd.; 2008. p. 2-14.

8. Erian I, Phillips CJC. Public understanding and attitudes towards meat chicken production and relations to consumption. Animals. 2017;7:20.

9. Wunderlich F, Al-Quraishy S, Steinbrenner H, Sies H, Dkhil MA. Towards identifying novel anti-Eimeria agents: trace elements, vitamins, and plantbased natural products. Parasitol Res. 2014;113:3547-56.

10. Allen PC, Lydon J, Danforth HD. Effects of components of Artemisia annua on coccidia infections in chickens. Poult Sci. 1997:6:1156-63.

11. Jiao J, Yang Y, Liu M, Li J, Cui Y, Yin S, et al. Artemisinin and Artemisia annua leaves alleviate Eimeria tenella infection by facilitating apoptosis of host cells and suppressing inflammatory response. Vet Parasitol. 2018;254:172-7.

12. Giannenas I, Florou-Paneri P, Papazahariadou M, Christaki E, Botsoglou $N A$, Spais AB. Effect of dietary supplementation with oregano essential oil on performance of broilers after experimental infection with Eimeria tenella. Arch Anim Nutr. 2003;57:99-106.

13. Pourali M, Kermanshahi H, Golian A, Razmi GR, Soukhtanloo M. Antioxidant and anticoccidial effects of garlic powder and sulfur amino acids on Eimeria-infected and uninfected broiler chickens. Iran J Vet Res. 2014;15:227-32.

14. Abbas RZ, lqbal Z, Akhtar MS, Khan MN, Jabbar A, Sandhu Z. Anticoccidial screening of Azadirachta indica (Neem) in broilers. Pharmacologyonline. 2006;3:365-71.

15. Marizvikuru M, Evison B, Michael C, Tinyiko EH. The in vitro studies on the effect of Aloe vera ((L.) Webb. \& Berth.) and Aloe spicata (L.f.) on the control of coccidiosis in chickens. Int J Appl Res Vet Med. 2006;4:128-33.

16. Jang IJ, Jun M, Lillehoj HS, Dalloul RA, Kong IK, Kim S, et al. Anticoccidial effect of green tea-based diets against Eimeria maxima. Vet Parasitol. 2007;144:172-5.

17. Awais MM, Akhtar M, Muhammad F, ul Haq A, Anwar Ml. Immunotherapeutic effects of some sugar cane (Saccharum officinarum L.) extracts against coccidiosis in industrial broiler chickens. Exp Parasitol. 2011;128:104-10.

18. Kim DK, Lillehoj HS, Lee SH, Jang SI, Lillehoj EP, Bravo D. Dietary Curcuma longa enhances resistance against Eimeria maxima and Eimeria tenella infections in chickens. Poult Sci. 2013;92:2635-43.

19. Abbas RZ, Colwell DD, Gilleard J. Botanicals: an alternative approach for the control of avian coccidiosis. Worlds Poult Sci J. 2012;68:203-15.

20. Muthamilselvan T, Kuo TF, Wu YC, Yang WC. Herbal remedies for coccidiosis control: a review of plants, compounds, and anticoccidial actions. Evid Based Complement Altern Med. 2016;2016:2657981.

21. Quiroz-Castaneda RE, Dantan-Gonzalez E. Control of avian coccidiosis: future and present natural alternatives. Biomed Res Int 2015;2015:430610.

22. del Cacho E, Gallego M, Francesch M, Quílez J, Sánchez-Acedo C. Effect of artemisinin on oocyst wall formation and sporulation during Eimeria tenella infection. Parasitol Int. 2010;59:506-11.
23. Fatemi A, Razavi MS, Asasi K, Goudarzi TM. Effects of Artemisia annua extracts on sporulation of Eimeria oocysts. Parasitol Res. 2015:114:1207-11.

24. Kim DK, Lillehoj HS, Lee SH, Lillehoj EP, Bravo D. Improved resistance to Eimeria acervulina infection in chickens due to dietary supplementation with garlic metabolites. Br J Nutr. 2013;109:76-88.

25. Arczewska-Włosek A, Świątkiewicz S. The effect of a dietary herbal extract blend on the performance of broilers challenged with Eimeria oocysts. J Anim Feed Sci. 2012;21:133-42.

26. Arczewska-Włosek A, Świątkiewicz S. Improved performance due to dietary supplementation with selected herbal extracts of broiler chickens infected with Eimeria spp. J Anim Feed Sci. 2013;22:257-63.

27. Masood S, Abbas RZ, labal Z, Mansoor MK, Sindhu ZUD, Zia MA, et al. Role of natural antioxidants for the control of coccidiosis in poultry. Pak Vet J. 2013;33:401-7.

28. Haug A, Thebo P, Mattsson JG. A simplified protocol for molecular identification of Eimeria species in field samples. Vet Parasitol. 2007;146:35-45.

29. Hodgson JN. Coccidiosis: oocyst counting technique for coccidiostat evaluation. Exp Parasitol. 1970;28:99-102.

30. Johnson J, Reid WM. Anticoccidial drugs: Lesion scoring techniques in battery and floor-pen experiments with chicken. Exp Parasitol. 1970:28:30-6.

31. De Pablos LM, dos Santos MF, Montero E, Garcia-Granados A, Parra A, Osuna A. Anticoccidial activity of maslinic acid against infection with Eimeria tenella in chickens. Parasitol Res. 2010;107:601-4.

32. Clarke L, Fodey TL, Crooks SRH, Moloney M, O'Mahony J, Delahaut P, et al. A review of coccidiostats and the analysis of their residues in meat and other food. Meat Sci. 2014;97:358-74.

33. Dar SA, Verma P, Ashfaque M, Zargar AA, Mir IA. Effect of garlic extract on haematobiochemical changes in Eimeria tenella infected broiler chicken. Natl Acad Sci Lett. 2014:37:311-6.

34. Franciosini MP, Casagrande-Proietti P, Forte C, Beghelli D, Acuti G, Zanichelli D, et al. Effects of oregano (Origanum vulgare L.) and rosemary (Rosmarinus officinalis L.) aqueous extracts on broiler performance, immune function and intestinal microbial population. J Appl Anim Res. 2016:44:474-9.

35. Roofchaee A, Irani M, Ebrahimzadeh MA, Akbari MR. Effect of dietary oregano (Origanum vulgare L) essential oils on growth performance, cecal microflora and serum antioxidant activity of broiler chickens. Afr J Biotechnol. 2011:10:6177-83.

36. Ghalamkari G, Toghyani M, Tavalaeian E, Landy N, Ghalamkari Z, Radnezhad $\mathrm{H}$. Efficiency of different levels of Satureja hortensis L. (savory) in comparison with an antibiotic growth promoter on performance, carcass traits, immune responses and serum biochemical parameters in broiler chickens. Afr J Biotechnol. 2011;10:13318-23.

37. Rajaian H, Aberumandi M, Jalaei J, Khosravi M. Satureja hortensis as a growth promoter in broiler chickens. Iran J Vet Res. 2014;15:149-53.

38. Bozkurt M, Aysul N, Küçükyilmaz K, Aypak S, Ege G, Catli AU, et al. Efficacy of in-feed preparations of an anticoccidial, multienzyme, prebiotic, probiotic, and herbal essential oil mixture in healthy and Eimeria spp.-infected broilers. Poult Sci. 2014;93:389-99.

39. Arczewska-Włosek A, Świątkiewicz S. The efficacy of selected feed additives in the prevention of broiler chicken coccidiosis under natural exposure to Eimeria spp. Ann Anim Sci. 2015;15:725-35.

40. Ahmadov El, Topciyeva ShA, Hasanova JV, Namazova AA. Effects of herbal plants on ducks and quail infected with Eimeria species. J Entomol Zool Stud. 2016:4:1150-2.

41. Xie G, Schepetkin IA, Quinn MT. Immunomodulatory activity of acidic polysaccharides isolated from Tanacetum vulgare L. Int Immunopharmacol. 2007;7:1639-50.

42. Hosseinzadeh H, Qotbi AAA, Seidavi AR, Norris D, Brown D. Effect of different levels of coriander (Coriandrum sativum) seed powder and extract on serum biochemical parameters, microbiota and immunity in broiler chicks. Sci World J. 2014;2014:628979.

43. Mohammad DAM, Ali HM, Atyha AH. Effects of Artemisia herba-alba and Urtica dioica on some blood parameters in broiler chickens infected experimentally with Eimeria tenella. Basrah J Vet Res. 2016;15:278-91.

44. Hussain K, lqbal Z, Abbas RZ, Khan MK, Saleemi MK. Immunomodulatory activity of Glycyrrhiza glabra extract against mixed Eimeria infection in chickens. Int J Agric Biol. 2017;19:928-32. 
45. Alhotan RA, Abudabos A. Anticoccidial and antioxidant effects of plants derived polyphenol in broilers exposed to induced coccidiosis. Environ Sci Pollut Res Int. 2019. https://doi.org/10.1007/s11356-019-04615-2.

46. Karunanidhi A, Thomas R, Belkum A, Neela V. In vitro antibacterial and antibiofilm activities of chlorogenic acid against clinical isolates of Stenotrophomonas maltophilia including the trimethoprim/sulfamethoxazole resistant strain. Biomed Res Int. 2013:2013:392058.

47. Sato Y, Itagaki S, Kurokawa T, Ogura J, Kobayashi M, Hirano T, et al. In vitro and in vivo antioxidant properties of chlorogenic acid and caffeic acid. Int J Pharm. 2011;403:136-8.
48. Idris M, Abbas RZ, Masood S, Rehman T, Farooq U, Babar W, et al. The potential of antioxidant rich essential oils against avian coccidiosis. Worlds Poult Sci J. 2017:73:89-104.

\section{Publisher's Note}

Springer Nature remains neutral with regard to jurisdictional claims in published maps and institutional affiliations.
Ready to submit your research? Choose BMC and benefit from:

- fast, convenient online submission

- thorough peer review by experienced researchers in your field

- rapid publication on acceptance

- support for research data, including large and complex data types

- gold Open Access which fosters wider collaboration and increased citations

- maximum visibility for your research: over $100 \mathrm{M}$ website views per year

At BMC, research is always in progress.

Learn more biomedcentral.com/submissions 